\title{
Usefulness of milnacipran in treating phantom limb pain
}

This article was published in the following Dove Press journal:

Neuropsychiatric Disease and Treatment

19 November 2012

Number of times this article has been viewed

\author{
Yasuhide Nagoshi' \\ Akira Watanabe' \\ Saiko Inoue' \\ Tomoki Kuroda ${ }^{2}$ \\ Mitsuo Nakamura ${ }^{3}$ \\ Yoshitake Matsumoto ${ }^{4}$ \\ Kenji Fukui ${ }^{3}$ \\ 'Department of Psychiatry \\ (Psychosomatic Medicine), Kyoto \\ First Red Cross Hospital, Kyoto, Japan; \\ ${ }^{2}$ Gojouyama Hospital, Nara, Japan; \\ ${ }^{3}$ Department of Psychiatry, Graduate \\ School of Medical Science, Kyoto \\ Prefectural University of Medicine, \\ Kyoto, Japan; ${ }^{4}$ Matsumoto Clinic, \\ Kyoto, Japan
}

Correspondence:Yasuhide Nagoshi Department of Psychiatry

(Psychosomatic Medicine), Kyoto First Red Cross Hospital, I5-749,

Honmachi, Higashiyama-ku, Kyoto-shi,

Kyoto 605-098I, Japan

Tel +8175561 II I I

Fax +81755616308

Email pandasportiva@yahoo.co.jp
Background: Amputation of an extremity often results in the sensation of a "phantom limb" where the patient feels that the limb that has been amputated is still present. This is frequently accompanied by "phantom limb pain". We report here the use of milnacipran, a serotonin and norepinephrine reuptake inhibitor, to treat phantom limb pain after amputation of injured or diseased limbs in three patients.

Methods and results: The severity of phantom pain before and during treatment was quantified using a visual analog scale. In one case, phantom limb pain responded partially to treatment with high doses of paroxetine, and then replacement with milnacipran further improved the pain relief and long-term full pain relief was achieved. In the two other cases, milnacipran was used as first-line treatment and phantom limb pain responded rapidly.

Conclusion: These results suggest that milnacipran administration may be useful in phantom limb pain, possibly as a first-line treatment.

Keywords: milnacipran, paroxetine, phantom limb pain, selective serotonin reuptake inhibitor (SSRI), serotonin and norepinephrine reuptake inhibitor (SNRI)

\section{Introduction}

Amputation of any of the extremities, such as an arm or a leg, often results in the sensation of a "phantom limb" where the patient feels that the extremity that has been amputated is still present. In up to $85 \%$ of cases, this sensation is accompanied by phantom limb pain. ${ }^{1-3}$ Spontaneous disappearance of phantom limb pain is usually very slow, taking many months and often years, and in many cases the pain becomes chronic with a major impact on the patient's quality of life. ${ }^{4}$

Common treatments for phantom limb pain include surgery, psychotherapy, and pharmacotherapy. Tricyclic antidepressants (TCAs) have been reported to have some efficacy in reducing phantom limb pain ${ }^{5,6}$ although this was not confirmed in a randomized trial. ${ }^{7}$ A recent extensive review concluded that larger and more rigorous randomized controlled trials are needed before any treatment can be recommended for phantom limb pain. ${ }^{8}$ The principal mechanism of TCAs is inhibition of reuptake of serotonin and norepinephrine. Milnacipran is a serotonin and norepinephrine reuptake inhibitor (SNRI) which is used as an antidepressant and in the treatment of various chronic pain disorders, including fibromyalgia. ${ }^{9-11}$ We report here the successful use of milnacipran in three cases of phantom limb pain. In addition to clinical descriptions, a $10 \mathrm{~cm}$ visual analog scale (VAS) ${ }^{12}$ was used to rate pain severity at different time points (Figure 1). 


\section{Case report I}

The patient, a 27-year-old male, was involved in a collision with a car while riding a motorcycle (see Figure 1A). His right leg was severed off at the knee and he suffered from traumatic hemopneumothorax and atelectasis due to fractured ribs. He was admitted to the orthopedics department of our hospital where he underwent amputation of his right leg at the level of the thigh. Hemopneumothorax and atelectasis were improved by conservative therapy. Phantom leg pain appeared within 24 hours of amputation. A non-steroidal anti-inflammatory analgestic, Diclofenac $75 \mathrm{mg}$ /day was administered, but was found to be ineffective and stopped. Six days after the accident, paroxetine $10 \mathrm{mg} /$ day was started, and 10 days later the dose was increased to $20 \mathrm{mg}$ /day. Five days later the patient was transferred to the psychiatry department.

The patient showed no signs of depression, scoring 38 points on the Zung Self-rating Depression scale (SDS). ${ }^{13}$ The phantom pain was diffuse and stronger at the distal end, and was accompanied by numbness and the occasional sensation of heat. The pain was continuous but varied in severity. Contact with the stump or tapping on the back of the head worsened the pain. Increased consciousness of the pain also increased pain severity.

Because of insufficient pain relief (pain VAS 6.6) at about 7 weeks after treatment initiation, the dose of paroxetine was increased to $30 \mathrm{mg} /$ day and a week later to $40 \mathrm{mg} /$ day. The frequency and severity of pain decreased and the patient reported feeling better (pain VAS 3.3). However, considerable phantom leg pain remained and the patient requested a change to a different drug. Thus, approximately 3 months after initiation of paroxetine treatment, it was replaced, in a stepwise manner, by milnacipran $100 \mathrm{mg} /$ day, and his phantom leg pain further improved, then he reported feeling almost no pain within a week (pain VAS 2.3). Milnacipran treatment was continued and he no longer spontaneously complained of phantom leg pain, and when asked, reported that he was hardly aware of it (pain VAS 0.6). Six months later, the dose of milnacipran was reduced to $75 \mathrm{mg}$ /day, with no apparent aggravation of symptoms.

\section{Case report 2}

The patient, a 28-year-old male, was involved in a collision with a car while riding a motorcycle (see Figure 1B). His right lower limb was severed off. He was admitted to the orthopedics department of our hospital. He underwent amputation of the lower right leg on the same day. After surgery, he suffered from insomnia and cried frequently. He was transferred to the psychiatry department 2 days later. Apart from crying, there was nothing else to suggest that he was suffering from depression (score 30 points on SDS).

The insomnia was improved by short-term administration of flunitrazepam $1 \mathrm{mg}$ /day and the patient stopped crying. About 2 weeks after amputation, the patient started to complain of phantom leg pain in the amputated limb. Diclofenac $75 \mathrm{mg} /$ day was administered, but was found to be ineffective and thus rapidly discontinued. Phantom leg pain, accompanied by a feeling of numbness, spread over the entire phantom leg. The pain was continuous but variable in severity (average pain VAS 8.0). When the patient was conscious of his phantom leg pain, the pain was more severe but subsided when he was occupied with other things, such as talking with people. Milnacipran administration was started at $25 \mathrm{mg} /$ day. A marked improvement in phantom leg pain was noticeable within 6 days (pain VAS 1.0), and the symptom had virtually disappeared by 25 days of treatment (pain VAS 0.1), with no recurrence.

\section{Case report 3}

The patient, a 67-year-old male, had been diagnosed with liver cancer at the age of 64 years and frequently underwent transcatheter arterial embolization and percutaneous ethanol injection therapy (see Figure 1C). Following reports of pain in the left upper arm, a diagnosis of pathological bone fracture resulting from metastasis of liver cancer was made. Transection at the level of the left scapula was carried out as a life-support procedure. Due to considerable preoperative anxiety and insomnia, the patient had an initial consultation in the psychiatry department prior to surgery, at which time a hypnotic, zolpidem at $10 \mathrm{mg} /$ day was administered.

For several days after surgery, the patient was delirious during the night. After discontinuation of zolpidem and administration of quetiapine $250 \mathrm{mg}$ /day, his delirious state subsided. After surgery, the patient complained of pain in the left shoulder which was initially limited to the surface of the stump. Three weeks later, he reported a heaviness and numbing pain in his (phantom) left elbow and wrist (pain VAS 4.0). Milnacipran $50 \mathrm{mg} /$ day was administered and significant pain relief was achieved within a week (pain VAS 2.0). A month later, the phantom arm pain had completely disappeared (pain VAS 0). Two months later, the patient reported that he again felt pain several times a week (pain VAS 2.0). The dose of milnacipran was increased to $75 \mathrm{mg} / \mathrm{day}$, which resulted in a reduction in pain severity and frequency, with the patient reporting only mild pain about once in every 2 weeks (pain VAS $0-1.0$ ). The patient continues to take milnacipran and reports no pain. 


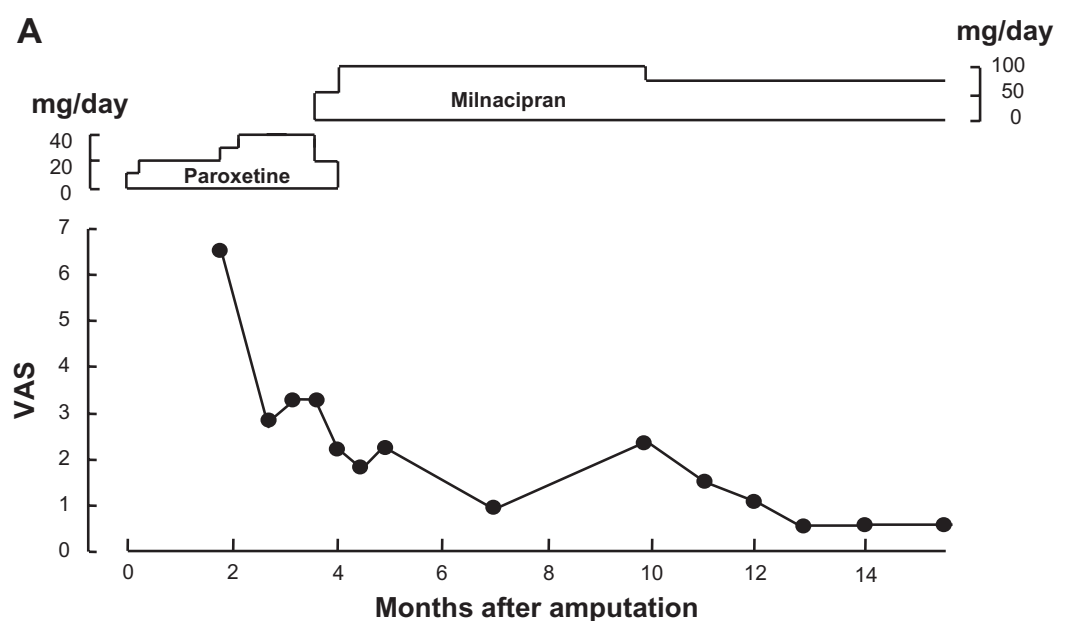

B
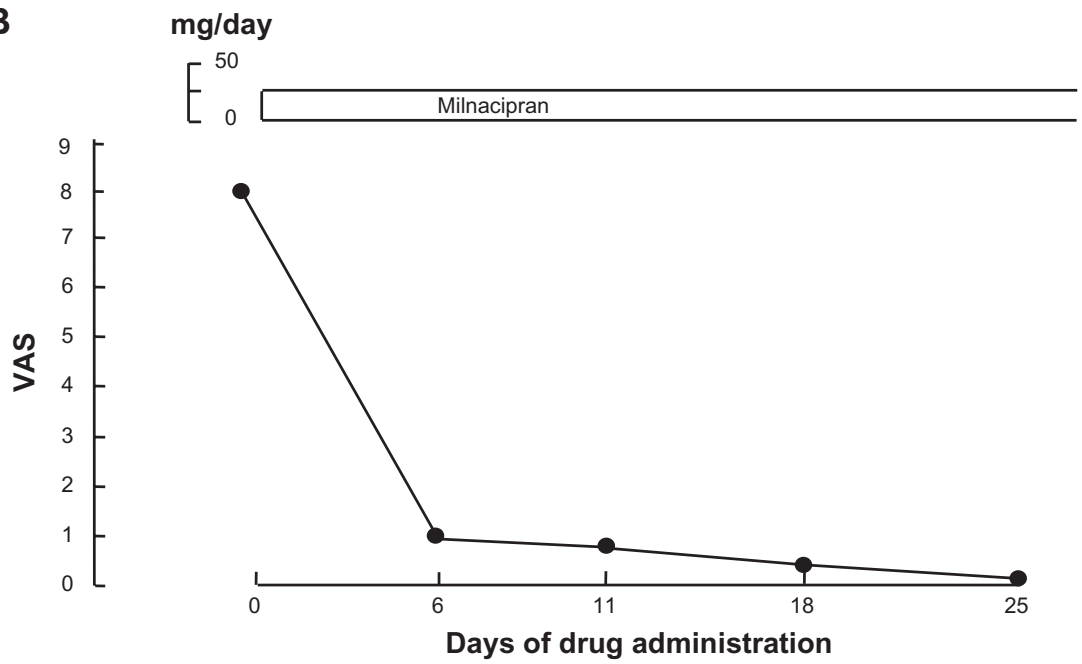

C

$\mathrm{mg} / \mathrm{day}$
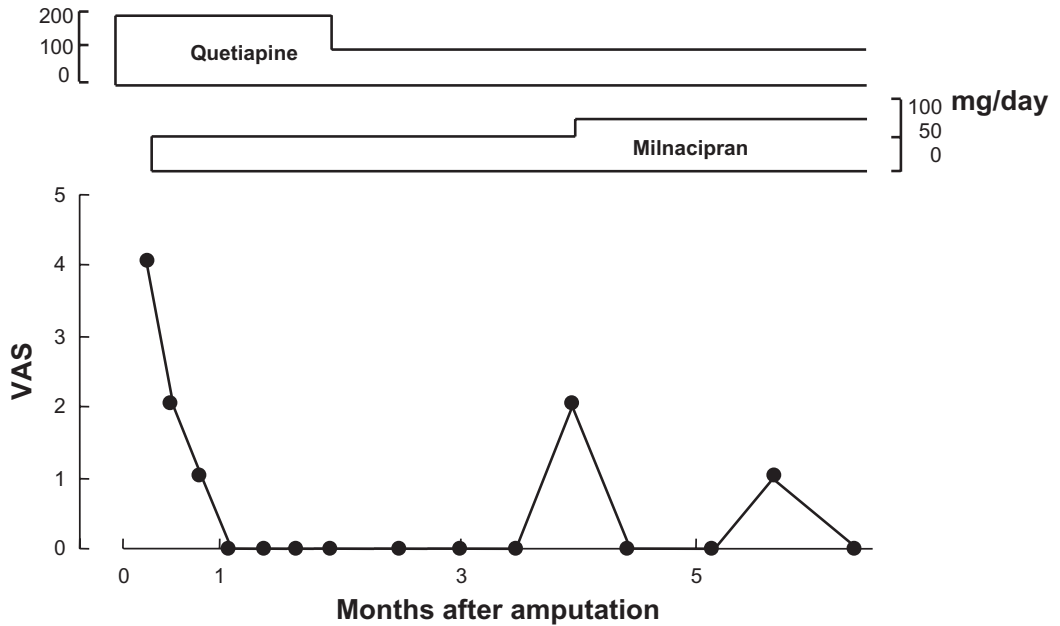

Figure I Change in phantom limb pain during therapy. (A) Case I shows initial use of paroxetine which was partially effective but required high doses. Stepwise switch to milnacipran continued to improve pain relief, leading to a long-term near-total absence of pain. (B) Case 2 shows a dramatic reduction in pain within 6 days of introduction of milnacipran. Total pain relief was obtained after less than 4 weeks of therapy. (C) Case 3 shows that administration of quetiapine to control delirium had no effect on pain relief produced by milnacipran, which was complete within a month. Subsequent resurgences of pain were controlled by increasing the dose of milnacipran. Abbreviation: VAS, visual analog scale for pain ${ }^{12}$ scored in $\mathrm{cm}$ on a $10 \mathrm{~cm}$ scale. 


\section{Discussion}

A variety of therapeutic approaches, including medication, have been used in the treatment for phantom limb pain. ${ }^{5}$ No medication has been found to be particularly effective, ${ }^{8}$ although TCAs have been used with some success. ${ }^{5,6}$ The mechanism of the analgesic effect of antidepressants is thought to involve activation of the descending pain control system from the brain stem to the dorsal horn of the spinal cord..$^{14,15}$ The same mechanism has been suggested for SNRIs, in particular milnacipran and duloxetine, which have been shown to be active in a variety of chronic pain syndromes, including fibromyalgia. ${ }^{9-11,16}$ This mechanism is supported by the fact that the medication works as well in nondepressed patients ${ }^{14,15}$ and the onset of pain relief is usually seen earlier than their antidepressant effect, and is frequently achieved at lower doses than those used to treat depression. ${ }^{11,16}$

In view of this, we have used milnacipran in the treatment of phantom limb pain. In 2005 we published, in Japanese, the first report of a case of successful treatment of phantom limb pain with milnacipran (case 1 described above). ${ }^{17}$ Another single case of the use of milnacipran in phantom limb pain has been briefly reported, where addition of milnacipran to a therapeutic cocktail of fluvoxamine, quetiapine, and etizolam resulted in the disappearance of phantom leg pain. ${ }^{18}$ A further recent brief report has been published of a case of phantom limb pain which was treated with some success using tramadol, and was further improved by addition of milnacipran. ${ }^{19}$ However, case 2 in the present paper is the first report of milnacipran being successfully used as monotherapy and first-line treatment of phantom limb pain.

Milnacipran was chosen because of its balanced action on serotonin and norepinephrine neurotransmission, ${ }^{14}$ since there is evidence to suggest that the norepinephrine system has a stronger influence than the serotonin system on pain mediation. ${ }^{20}$ Indeed, selective serotonin reuptake inhibitors (SSRIs) have frequently been found to be only weakly active. ${ }^{8}$ Other important properties in favor of the use of milnacipran are its good tolerability and lack of interaction with cytochrome $\mathrm{P} 450$ metabolic enzymes. ${ }^{10}$

Case 1 (Figure 1A) is an example of insufficient pain relief obtained with a SSRI, paroxetine, which required high doses. Replacement with milnacipran resulted in full pain relief which was sustained over time. In case 2 (Figure 1B), milnacipran, given alone as first-line therapy, was rapidly effective within 6 days. In case 3 (Figure 1C), quetiapine was administered to control delirium, but relief of phantom limb pain was obtained only when milnacipran was introduced. The effect was rapid (within a week) and resulted in a virtual absence of pain. Subsequent resurgence of pain was successfully managed by increasing the dose of milnacipran.

None of the three patients reported here suffered from depression, as indicated by clinical examination and low SDS scores, suggesting that milnacipran was acting directly as an analgesic and not indirectly via an antidepressant effect. Milnacipran, in all three cases, produced rapid and near-total relief from phantom limb pain, suggesting that milnacipran may be useful in the treatment of phantom limb pain, possibly as a first-line agent.

\section{Disclosure}

The authors report no conflicts of interest in this work.

\section{References}

1. Manchikanti L, Singh V. Managing phantom pain. Pain Physician. 2004; 7:365-375.

2. Parkes CM. Factors determining the persistence of phantom pain in the amputee. J Psychosom Res. 1973;17:97-108.

3. Iacono RP, Linford J, Sandyk R. Pain management after lower extremity amputation. Neurosurgery. 1987;20:496-500.

4. Bosmans JC, Suurmeijer TP, Hulsink M, van der Schans CP, Geertzen JH, Dijkstra PU. Amputation, phantom pain and subjective well-being: a qualitative study. Int $J$ Rehabil Res. 2007;30:1-8.

5. Harwood DD, Hanumanthu S, Stoudemire A. Pathophysiology and management of phantom limb pain. Gen Hosp Psychiatry. 1992;14:107-118.

6. Iacono RP, Sandyk R, Bamford CR, Awerbuch G, Malone JM. Postamputation phantom pain and autonomous stump movements responsive to doxepin. Funct Neurol. 1987;2:343-348.

7. Robinson LR, Czerniecki JM, Ehde DM, et al. Trial of amitriptyline for relief of pain in amputees: results of a randomized controlled study. Arch Phys Med Rehabil. 2004;85:1-6.

8. Alviar MJ, Hale T, Dungca M. Pharmacologic interventions for treating phantom limb pain. Cochrane Database Syst Rev. 2011;7:CD006380.

9. Ormseth MJ, Eyler AE, Hammonds CL, Boomershine CS. Milnacipran for the management of fibromyalgia syndrome. J Pain Res. 2010;3: $15-24$.

10. Owen RT. Milnacipran hydrochloride: its efficacy, safety and tolerability profile in fibromyalgia syndrome. Drugs Today (Barc). 2008;44:653-660.

11. Briley M. Clinical experience with dual action antidepressants in different chronic pain syndromes. Hum Psychopharmacol. 2004; 19 Suppl 1:S21-S25.

12. De Loach LJ, Higgins MS, Caplan AB, Stiff JL. The visual analog scale in the immediate postoperative period: intrasubject variability and correlation with a numeric scale. Anesth Analg. 1998;86:102-106.

13. Zung WW. A self-rating depression scale. Arch Gen Psychiatry. 1965;12:63-70.

14. Stahl SM. Fibromyalgia - pathways and neurotransmitters. Hum Psychopharmacol. 2009;24 Suppl 1:S11-S17.

15. Kranzler JD, Gendreau JF, Rao SG. The psychopharmacology of fibromyalgia: a drug development perspective. Psychopharmacol Bull. 2002;36:165-213

16. Moret C, Briley M. Antidepressants in the treatment of fibromyalgia. Neuropsychiatr Dis Treat. 2000;2:537-548.

17. NagoshiY, Matsumoto Y, Fukui K. The effect of milnacipran on phantom limb pain: a case report. Jpn J Psychosom Med. 2005;45:627-634. Japanese. 
18. Sato K, Higuchi H, Hishikawa Y. Management of phantom limb pain and sensation with milnacipran. J Neuropsychiatry Clin Neurosci. 2008;20:368

19. Chalana H. A case report of milnacipran in phantom limb pain. Asian J Psychiatr. 2010;3:155-156.
20. Max MB. Treatment of post-herpetic neuralgia: antidepressants. Ann Neurol. 1994;35 Suppl 1:S50-S53.

\section{Publish your work in this journal}

Neuropsychiatric Disease and Treatment is an international, peerreviewed journal of clinical therapeutics and pharmacology focusing on concise rapid reporting of clinical or pre-clinical studies on a range of neuropsychiatric and neurological disorders. This journa is indexed on PubMed Central, the 'PsycINFO' database and CAS
The manuscript management system is completely online and includes a very quick and fair peer-review system, which is all easy to use. Visit http://www.dovepress.com/testimonials.php to read real quotes from published authors.

Submit your manuscript here: http://www.dovepress.com/neuropsychiatric-disease-and-treatment-journal 